\title{
Isolation and characterization of 9 polymorphic microsatellite markers for the endangered boring giant clam (Tridacna crocea) and cross-priming testing in three other Tridacnid species
}

\author{
Timery S. DeBoer $\cdot$ Paul H. Barber
}

Received: 4 May 2010/Accepted: 6 May 2010/Published online: 19 May 2010

(c) The Author(s) 2010. This article is published with open access at Springerlink.com

\begin{abstract}
We report the development and characterization of nine microsatellite markers from the Tridacna crocea genome. In a wild population of 20 individuals from Ulugan Bay in the Republic of the Philippines, we observed an average of 9 alleles per locus and expected heterozygosity ranging from 0.41 to 0.92 . Cross-species priming was tested in three additional Tridacna species with moderate success. These markers will be used in studies of fine-scale population genetic structure and gene flow in $T$. crocea. The markers may also be useful in a forensic context by identifying source populations of giant clams collected illegally for the live aquarium trade, while protecting legal exports from aquaculture facilities.
\end{abstract}

Keywords Boring giant clam - Tridacna crocea . Microsatellites · Symbiodinium

Giant clams are an important part of coral reef habitats, providing reef stability and settlement substrate. Individuals are harvested for the aquarium trade, subsistence food, and for the shell trade (Copland and Lucas 1988) resulting in population decline due to overfishing. All species are listed

Electronic supplementary material The online version of this article (doi:10.1007/s12686-010-9249-7) contains supplementary material, which is available to authorized users.

T. S. DeBoer $(\bowtie)$

Biology Department, Boston University, 5 Cummington St,

Boston, MA 02215, USA

e-mail: timery.deboer@gmail.com

P. H. Barber

Department of Ecology and Evolutionary Biology, University of California, Los Angeles, 621 Charles E. Young Dr. South, Los Angeles, CA 90095, USA in Appendix II of CITES (UNEP-WCMC 2007) and on the IUCN Red List of Threatened Species (Mollusk Specialist Group 1996). Restocking efforts are ongoing, especially in the Philippines (Gomez and Mingoa-Licuanan 2006). In order to provide genomic tools for inferring fine-scale population genetic structure and demographic parameters on recent time scales, we developed 9 new microsatellite markers for the boring giant clam (Tridacna crocea) and tested for cross-amplification in three congeners.

We isolated genomic DNA from fresh muscle tissue of one individual obtained legally from the aquarium trade using the QIAGEN DNeasy Tissue Kit and digested with a combination of AluI, XmnI, and RsaI. STR enrichment followed Glenn and Schable (2005) except for our choice of biotinylated oligonucleotide probes: $(\mathrm{AC})_{13}(\mathrm{AAC})_{6}$, $(\mathrm{ACAT})_{8},(\mathrm{ACTC})_{6},(\mathrm{AGAT})_{8}$, and $(\mathrm{ATCC})_{5}$. Plasmids were cloned with PROMEGA pGEM-T Vector System I cloning kit according to the manufacturer's protocols and grown on LB agar plates containing ampicillin and X-gal. Positive clones were recovered in PCR reactions using T7 and M13R universal primers and sequenced using the BigDye Terminator method (ABI) on an ABI 3730. Sequences were edited in Sequencher 4.6 (Gene Codes) and short tandem repeats (STRs) were identified with the Simple Sequence Repeat Identification Tool (Temnykh et al. 2001). We designed primers in PRIMER3 (Rozen and Skaletsky 2000) and screened them using AUTODIMER (Vallone and Butler 2004).

We assessed allelic variation in 20 individuals from Ulugan Bay, Philippines. Cross-priming was tested on 8 individual T. maxima and T. squamosa and 3 individual T. gigas. Genomic DNA was extracted using $10 \%$ Chelex (Walsh et al. 1991). PCR amplification was in $10 \mu \mathrm{l}$ reactions containing $1.0 \mu \mathrm{l}$ DNA template, $0.25 \mathrm{U}$ Taq Gold polymerase $(\mathrm{ABI}), 1 \mu \mathrm{l} 10 \times \mathrm{PCR}$ Buffer, $1 \mu \mathrm{l} \mathrm{dNTPs}$ 


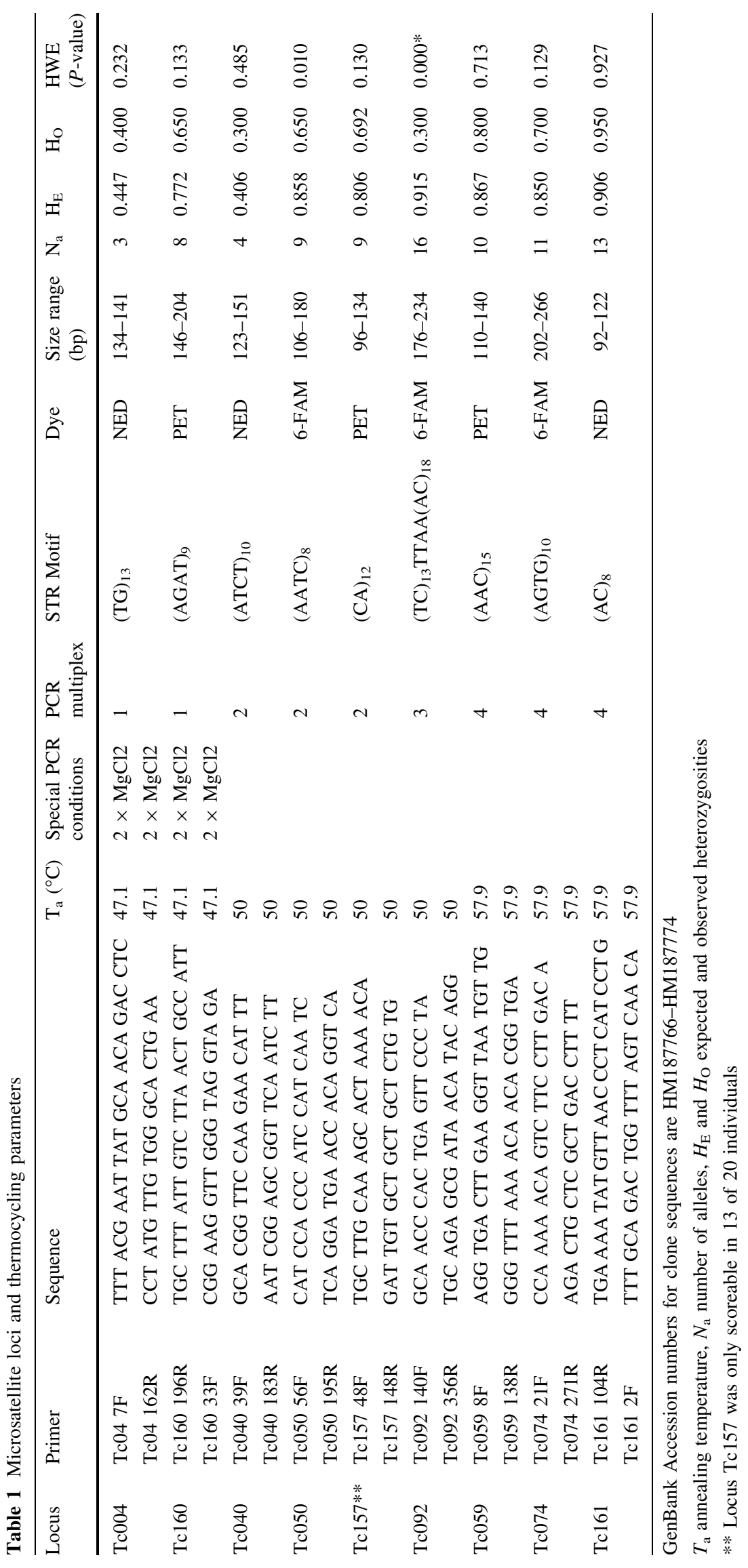


Table 2 Cross-priming success in 3 additional Tridacna species

\begin{tabular}{|c|c|c|c|c|c|c|c|c|c|}
\hline \multirow[t]{2}{*}{ Locus } & \multicolumn{3}{|c|}{ T. maxima $(n=8)$} & \multicolumn{3}{|c|}{ T. squamosa $(n=8)$} & \multicolumn{3}{|c|}{ T. gigas $(n=3)$} \\
\hline & $N_{\text {indiv }}$ & Size range (bp) & $N_{\mathrm{a}}$ & $N_{\text {indiv }}$ & Size range (bp) & $N_{\mathrm{a}}$ & $N_{\text {indiv }}$ & Size range (bp) & $N_{\mathrm{a}}$ \\
\hline Тc004 & 1 & $145-149$ & 2 & 3 & $141-143$ & 2 & 0 & NA & - \\
\hline Tc160 & 1 & 150 & 1 & 0 & NA & - & 0 & NA & - \\
\hline Tc040 & 7 & $123-139$ & 5 & 1 & 135 & 1 & 3 & 100 & 1 \\
\hline Tc050 & 7 & $86-210$ & 7 & 8 & $174-194$ & 5 & 3 & 92 & 1 \\
\hline Tc092 & 3 & $180-218$ & 4 & 0 & NA & - & 2 & $84-224$ & 2 \\
\hline Tc059 & 5 & $95-98$ & 2 & 0 & NA & - & 0 & NA & - \\
\hline Tc074 & 5 & $226-238$ & 3 & 5 & 230 & 1 & 0 & NA & - \\
\hline Tc157 & 0 & NA & & 6 & $96-108$ & 4 & 2 & 146 & 1 \\
\hline Tc161 & 5 & $76-90$ & 2 & 6 & 90-94 & 2 & 0 & NA & - \\
\hline
\end{tabular}

$N_{\text {indiv }}$ number of individuals successfully genotyped, $N_{\text {a }}$ number of alleles

(8 $\mathrm{mM}), 0.8 \mu \mathrm{l} \mathrm{MgCl}_{2}(25 \mathrm{mM})$, and $0.5 \mu \mathrm{l}$ of each primer $(10 \mathrm{mM})$. For loci Tc004 and Tc160 the amount of $\mathrm{MgCl}_{2}$ was doubled and water reduced to a final volume of $10 \mu \mathrm{l}$. Thermocycling parameters were: $1 \times 94^{\circ} \mathrm{C}(10 \mathrm{~min}), 30 \times$ [30 s at $94^{\circ} \mathrm{C}, 30 \mathrm{~s} \mathrm{~T}_{\mathrm{a}}{ }^{\circ} \mathrm{C}, 40 \mathrm{~s}$ at $72^{\circ} \mathrm{C}$ ], and $1 \times 72^{\circ} \mathrm{C}$ (60 min). Annealing temperatures $\left(\mathrm{T}_{\mathrm{a}}\right)$ for each locus are in Table 1.

Hardy-Weinberg equilibrium (HWE) and linkage disequilibrium were assessed in ARLEQUIN 3.11 (Excoffier et al. 2005). Locus Tc157 amplified well in all samples, but was only scoreable in some individuals due to multiple peaks. Locus Tc092 showed a significant departure from HWE after Bonferroni correction (Table 1). Linkage disequilibrium was only significant in 1 out of 36 pairwise comparisons at the $P<0.01$ level (Tc074 vs. Tc092) indicating virtually no linkage among loci.

Since no species-specific PCR optimization was attempted, the results reported here represent a minimum rate of cross-species primer conservation. The test resulted in 5 loci amplifying in T. maxima (5 polymorphic); 4 loci amplifying in $T$. squamosa (3 polymorphic); and 4 loci amplifying in $T$. gigas (1 polymorphic) (Table 2). The $T$. gigas were from cultured stocks, therefore the lack of polymorphism is expected and may not represent diversity in natural populations.

A technical challenge to developing microsatellites in this species is targeting the host genome rather than that of symbiotic dinoflagellates (Symbiodinium spp.). Symbionts are restricted to mantle tissue in giant clams, therefore we extracted genomic DNA from muscle tissue for primer development. To verify that none of our primers amplify symbiont DNA, we tested them on 7 symbiont types using PCR conditions as described above (Table S1). Excepting Tc004, no significant amplification was achieved in the range of allele sizes reported for $T$. crocea and we are confident that the loci developed are specific to giant clam DNA. For Tc004, a 128 bp fragment was amplified in two isolates. This is a common allele in T. crocea (T.S. DeBoer unpublished data); therefore, caution should be employed when using this locus.

Population genetic studies using mtDNA show strong structure in T. crocea (DeBoer et al. 2008, Kochzius and Nuryanto 2008). Microsatellites are expected to be more variable, and one application where this would be useful is forensic identification of clams sold in the aquarium trade. It should be possible to identify source regions for traded clams, as well as distinguish wild from cultured stocks. This would assist efforts to stop illegal trade in these internationally protected species. These markers will also be useful for inferring modern genetic connectivity and gene flow among natural and restored populations.

Acknowledgments We thank EJ Sbrocco for help with marker development. S Santos provided Symbiodinium cultures, with DNA isolated by AS Correa and AC Baker. Funding was provided by NSF (Barber, OISE-0730256) and the AMNH (DeBoer). Sample collection and data analysis were completed in the Philippines at De La Salle University with MCA Lagman under a permit from the Bureau of Fisheries and Research.

Open Access This article is distributed under the terms of the Creative Commons Attribution Noncommercial License which permits any noncommercial use, distribution, and reproduction in any medium, provided the original author(s) and source are credited.

\section{References}

Copland JW, Lucas JS (1988) Giant clams in Asia and the Pacific. Australian Center for International Agricultural Research, Canberra

DeBoer TS, Subia MD, Ambariyanto Erdmann MV, Kovitvongsa K, Barber PH (2008) Phylogeography and limited genetic connectivity in the endangered boring giant clam across the Coral Triangle. Conserv Biol J 22:1255-1266

Excoffier L, Laval G, Schneider S (2005) Arlequin, version 3.0: an integrated software package for population genetics data analysis. Evol Bioinform Online 1:47-50

Glenn TC, Schable NA (2005) Isolating microsatellite DNA loci. Methods Enzymol 395:202-222 
Gomez ED, Mingoa-Licuanan SS (2006) Achievements and lessons learned in restocking giant clams in the Philippines. Fish Res 80:46-52

Kochzius M, Nuryanto A (2008) Strong genetic structure in the boring giant clam Tridacna crocea across the Indo-Malay Archipelago: implications related to evolutionary processes and connectivity. Mol Ecol 17:3775-3787

Mollusk Specialist Group (1996) Tridacna crocea. In: IUCN 2006. 2006 IUCN Red List of Threatened Species

Rozen S, Skaletsky H (2000) Primer 3 on the WWW for general users and for biologist programmers. In: Krawetz S, Misener S (eds) Bioinformatics methods and protocols: methods in molecular biology. Humana Press, Totowa, pp 365-386
Temnykh S, DeClerck G, Lukashova A et al (2001) Computational and experimental analysis of microsatellites in rice (Oryza sativa L.): frequency, length variation, transposon associations, and genetic marker potential. Genome Res 11:1441-1452

UNEP-WCMC (2007) UNEP-WCMC Species Database: CITESListed Species

Vallone PM, Butler JM (2004) Autodimer: a screening tool for primer-dimer and hairpin structures. BioTechniques 37:226-231

Walsh PS, Metzger DA, Huiguchi R (1991) Chelex 100 as a medium for simple extraction of DNA for PCR-based typing from forensic material. BioTechniques 10:506-513 